Article

\title{
Stock Prices of Renewable Energy Firms: Are There Asymmetric Responses to Oil Price Changes?
}

\author{
Donggyu Lee ${ }^{1}$ and Jungho Baek ${ }^{2, *}$ (1) \\ 1 Department of Energy Systems Engineering, College of Engineering, Seoul National University, \\ Seoul 03080, Korea; ksg0307@snu.ac.kr \\ 2 Department of Economics, School of Management, University of Alaska Fairbanks, \\ Fairbanks, AK 99775, USA \\ * Correspondence: jbaek3@alaska.edu
}

Received: 2 September 2018; Accepted: 19 October 2018; Published: 5 November 2018

\begin{abstract}
This article revisits the question of whether crude oil prices have a positive effect on stock the prices of renewable energy firms. To examine this question carefully, we allow for the asymmetric effects of oil price changes in our modeling process, using the nonlinear autoregressive distributed lag (ARDL) approach. We find that changes in oil prices indeed have a significant, positive short-run effect on renewable energy stock prices in an asymmetric manner. However, this short-run effect does not appear to last in the long-run.
\end{abstract}

Keywords: asymmetry; nonlinear ARDL; oil prices; renewable energy; stock prices

\section{Introduction}

The conventional media wisdom suggests that the price rise of crude oil tends to positively impact stock prices of renewable energy firms because rising oil prices make renewable energy more competitive against petroleum in the energy market. Is the proposed link empirically valid? In this short article, we employ one of the recently most widely used time series models-an autoregressive distributed lag (ARDL) approach ${ }^{1}$ - to show that there is some evidence that the hike in the price of crude oil increases renewable energy stock prices, holding other factors (e.g., stock prices of technology firms and interest rates) fixed. Our main contribution to the existing literature is to pay close attention to the issue of whether oil prices have an asymmetric or symmetric effect on stock prices of renewable energy firms.

Many studies have investigated the independent effect of crude oil prices on stock prices of renewable energy firms over the past decade. Examples includes, but are not limited to, Irene Henriques (2008), Kumar et al. (2012), Sadorsky (2012), Broadstock et al. (2012), Managi and Okimoto (2013), Cummins et al. (2014), Bondia et al. (2016), Reboredo (2015), Reboredo et al. (2017). The empirical evidence provided by those researchers is rather mixed. For example, Irene Henriques (2008) and Sadorsky (2012) report that oil price shocks have little effect on the stock prices of renewable energy firms. Reboredo (2015), on the other hand, provides evidence that oil prices indeed have a positive effect on renewable energy firms' stock prices.

1 Since the pioneering work by Pesaran et al. (2001), the ARDL approach has been one of the most widely used methods in many fields of empirical research. Some examples include the following: Baek (2007), Baek and Koo (2009), and Bahmani-Oskooee and Baek (2015) for international trade; Sari et al. (2008); Ghosh (2009), Reynolds and Baek (2012), Stambuli (2013), Tappen and Baek (2016), and Shin et al. (2018) for energy economics; Jalil and Mahmud (2009), Iwata et al. (2010), Baek and Seok Kim (2013), and Baek and Pride (2014) for environmental economics; and Chaudhuri and Smiles (2004), Humpe and Macmillan (2009), Pilinkus (2010), and Bekhet and Matar (2013) for financial markets. 
The main factor contributing to the mixed findings may be closely associated with neglecting the possibility of the asymmetric effects of oil price shocks on stock prices of renewable energy firms, although investors' expectations and responses to an oil price hike are very likely to differ from their expectations and responses to an oil price drop in the real world. ${ }^{2}$ In other words, the existing studies do not directly allow for the asymmetrical effects of oil prices in the modeling process and cast doubts on their conclusions. Hence, further testing of the topic is warranted, which is what we intend to do in this article.

It should be emphasized at the onset that many studies use time series methods in examining the oil price stock market nexus and our paper is essentially part of them. Given the modeling approach, these studies can be classified into two groups. The first group uses nonstructural VAR/VEC models in tackling the issue (e.g., Huang et al. 1996; Sadorsky 1999; Papapetrou 2001; Park and Ratti 2008; Cong et al. 2008; Masih et al. 2011; Cunado and Gracia 2014). For example, Huang et al. (1996) and Sadorsky (1999) use a VAR model to analyze the effect of oil prices on U.S. stock markets. They conclude that oil price movements are important in explaining stock returns. Masih et al. (2011) and Bondia et al. (2016) confirm the findings of Huang et al. (1996) and Sadorsky (1999) using a VEC model. The second group addresses the oil price stock market nexus using a structural VAR model (e.g., Kilian and Park 2009; Basher and Sadorsky 2006; Wang et al. 2013; Fang and You 2014; Kang et al. 2015). For example, Kilian and Park (2009) use a structural VAR model and show that U.S. stock returns differ substantially depending on whether oil price changes are caused by supply or demand shocks in the oil market. However, a few studies have sought to address the possibility of the asymmetrical effects of oil prices.

The paper is organized as follows. The models and applications of an ARDL method are presented first. This is followed by a description of the data which consists of monthly observations over the period January 2002 to December 2016. Our empirical results are then discussed. In the final section, we provide our summary and conclusion.

\section{Models and Methods}

When examining the effect of oil prices on stock prices of renewable energy firms, we rely on an empirical framework developed by Irene Henriques (2008), and Managi and Okimoto (2013). In its basic form, stock prices of renewable energy firms are determined by the model:

$$
s p r_{t}=\beta_{0}+\beta_{1} \operatorname{cop}_{t}+\beta_{2} s p t_{t}+\beta_{3} i n t_{t}+u_{t}
$$

where $s p r_{t}$ is the natural log of stock prices of renewable energy firms; cop $p_{t}$ is the natural log of crude oil prices; $s p t_{t}$ is the natural log of stock prices of technology firms; int $t_{t}$ is the interest rate; and $u_{t}$ is the error term. If rising oil prices tend to encourage the use of renewable energy sources as a viable alternative for petroleum and increase stock prices of renewable energy firms, then $\beta_{1}>0$. Given the fact that stock investors tend to view renewable energy firms as identical with high technology firms, stock prices of technology firms are likely to have a significant influence on stock prices of renewable energy firms. By including $s p t_{t}$ explicitly in the model, therefore, we are able to control for its effect on $s p r_{t}$. If the two stock prices move in the same direction, then $\beta_{2}>0$. Finally, if stock prices move inversely to changes in interest rate as economic theory suggests, then $\beta_{3}<0$.

2 Changes in stock prices of renewable energy are more likely to react to higher oil prices. When high oil prices are expected to be maintained, for example, people are motivated to seek out alternative energy sources like solar and wind power, which increasingly compete with fossil fuels, thereby resulting in a surge in the price of alternative energy stocks. Although falling oil prices may swing away from people's attention from renewable sources, concerns about greenhouse-gas emissions are still likely to encourage the development of alternatives, thereby mitigating a drop in the price of alternative energy stocks. Accordingly, an asymmetrical price response would make some sense on the stock prices of renewable energy firms. To the best of our knowledge, Kyritsis and Serletis (2017) is perhaps the only study considering the asymmetrical effects of oil prices when examining the topic. Using a GARCH model, they show that oil price fluctuations have little effect on renewable stock prices so that the asymmetrical effects do not exist. 
Notably, the underlying assumption in Equation (1) is that changes in crude oil prices have a symmetrical effect on the renewable energy stock prices. In other words, if a one percent increase in oil prices increases the stock price by, say, $x \%$, a one percent decrease in oil prices should decrease it by $x \%$ as well. If not, then oil price changes are likely to have asymmetrical effects. To address asymmetrical effects of oil price changes adequately, Umekwe and Baek (2017) decompose oil price changes into two variables-one involving only oil price increases $\left(P O S_{t}\right)$ and the other one involving only oil price decreases $\left(N E G_{t}\right)$ :

$$
\begin{aligned}
& \operatorname{POS}_{t}=\sum_{j=1}^{t} \Delta \ln c o p_{j}^{+}=\sum_{j=1}^{t} \max \left(\Delta \ln c o p_{j}, 0\right) \\
& N E G_{t}=\sum_{j=1}^{t} \Delta \ln c o p_{j}^{-}=\sum_{j=1}^{t} \min \left(\Delta \ln c o p_{j}, 0\right)
\end{aligned}
$$

In order to perform the ARDL modeling that allows for asymmetrical effects of oil price changes, we first replace variable $c_{0} p_{t}$ in Equation (1) by $P O S_{t}$ and $N E G_{t}$, and then transform the original model into an error-correction model by incorporating the short-run dynamics among the variables. ${ }^{3}$ Hence, the model could give the results of both short-run dynamics and long-run dynamics.

$$
\begin{gathered}
\Delta s p r_{t}=\beta_{0}+\sum_{k=1}^{p} \beta_{k 1} \Delta s p r_{t-k}+\sum_{k=0}^{p} \beta_{k 2} \Delta \text { POS }_{t-k}+\sum_{k=0}^{p} \beta_{k 3} \Delta N E G_{t-k}+\sum_{k=0}^{p} \beta_{k 4} \Delta s p t_{t-k} \\
+\sum_{k=0}^{p} \beta_{k 5} \Delta i n t_{t-k}+\theta_{0} s p r_{t-1}+\theta_{1} \text { POS }_{t-1}+\theta_{2} N E G_{t-1}+\theta_{3} s p t_{t-1}+\theta_{4} i n t_{t-1}+\xi_{t}
\end{gathered}
$$

Since the inclusion of $P O S_{t}$ and $N E G_{t}$ incorporates nonlinearity into the analysis, Equation (4) is labeled as the nonlinear ARDL model (Shin et al. 2014). The coefficients of the first differences represented by $\beta_{k 1}$ to $\beta_{k 4}$ allow us to study the short-run dynamics in the relationship among the variables. The coefficients of $\theta_{1}$ to $\theta_{3}$ by normalizing the coefficient of $\theta_{0}$ describe the long-run stock price relationship. ${ }^{4}$ After Equation (4) is estimated, short- and long-run asymmetrical effects are said to be present if $\sum \beta_{k 2} \neq \sum \beta_{k 3}$ and $\theta_{1} / \theta_{0} \neq \theta_{2} / \theta_{0}$, respectively. For this purpose, we carry out the Wald test.

\section{Data}

Monthly data relating to the period of January 2002 to December 2016 are used for estimating Equation (4). ${ }^{5}$ The WilderHill New Energy Global Innovation Index (NEX) is used as a proxy for stock prices of renewable energy firms $\left(s p r_{t}\right)$ and is taken from Bloomberg. NEX represents a global index of 94 companies listed on 28 exchanges in 22 countries whose technologies focus on the generation and use of cleaner energy. The index currently comprises companies from all around the world, 39.0\% of Americas, $31.5 \%$ of Europe, Middle East \& Africa, and 29.5\% of Asia \& Oceania. In terms of the business sector, the index is composed of $32.2 \%$ of energy efficiency, $30.8 \%$ of wind power, and $19.1 \%$

3 It is important to note that the ARDL approach has certain econometric advantages in comparison to standard cointegration methods (i.e., Johansen and Juselius 1990). First, the ARDL can be used irrespective of whether the regressors are I(0) or I(1); hence, this method does not require the same order of integration among variables and pre-testing unit roots. Second, since an error-correction model (ECM) can be derived from the ARDL via a simple linear transformation, it is a very convenient tool to estimate the short- and long-run parameters of the model simultaneously. Third, the ARDL is more robust and performs better for finite sample size (small sample size) than conventional cointegration methods.

4 It is worth emphasizing that the short- and long-run estimates in Equation (4) are econometrically meaningful; a cointegration relationship should hold among the selected variables. For this, the null of the nonexistence of the long-run relationship, namely $\theta_{0}=\theta_{1}=\theta_{2}=\theta_{3}=\theta_{4}=0$ is tested. This can be implemented using an F-test with two sets of asymptotic critical values tabulated by Pesaran et al. (2001) in which a lower critical value assumes to be $I(0)$ regressor and an upper value assumes to be $I(1)$. This is why the ARDL is called a bounds testing procedure. If the calculated F-statistic lies outside the upper critical level of the critical bounds, the null can be rejected, indicating that the variables are cointegrated.

5 Although NEX can be collected from September 1999, the NYSE Arca Tech 100 Index can only be traced back to January 2002. For this reason, we compile the data starting from January 2002. 
of solar power. The West Texas Intermediate (WTI) spot prices $\left(\operatorname{cop}_{t}\right)$ are used as a proxy for crude oil prices and is obtained from the U.S. Energy Information Administration (EIA). The NYSE Arca Tech 100 Index is used as a proxy for stock prices of technology companies $\left(s p t_{t}\right)$ and is collected from Bloomberg. The index is a price-weighted index of 100 technology-related companies in 16 different industries such as computer hardware, software, semiconductors, telecom, data storage, electronics \& healthcare equipment. The 10-year treasury constant maturity rate is used as a proxy for interest rates $\left(\right.$ int $\left._{t}\right)$ and is taken from the Federal Reserve Bank of St. Louis. Finally, descriptive statistics of data are summarized in Table 1.

Table 1. Descriptive Statistics.

\begin{tabular}{lcccc}
\hline & Mean & Standard Deviation & Min & Max \\
\hline spr $_{t}$ & 199.869 & 78.956 & 95.280 & 455.190 \\
cop $_{t}$ & 67.074 & 26.764 & 19.720 & 133.880 \\
spt $_{t}$ & 1104.542 & 496.679 & 385.730 & 2153.540 \\
int $_{t}$ & 3.347 & 1.084 & 5.280 & 1.500 \\
\hline
\end{tabular}

\section{The Results}

In this section, we test whether changes in oil prices have an asymmetric effect on stock prices of renewable energy firms. For this purpose, we first impose a maximum lag length of 3 months on each of the first-differenced variables in Equation (4). The Akaike Information Criterion (AIC) then determines the $A R D L(2,1,3,1,1)$ as the optimal model specification. Table 2 contains the short-and long-run results.

Table 2. Results of nonlinear ARDL model.

\begin{tabular}{|c|c|c|c|c|}
\hline \multicolumn{5}{|c|}{ Panel A: Short-Run Coefficient Estimates } \\
\hline \multirow{3}{*}{ Independent Variables } & \multicolumn{4}{|c|}{ Dependent Variable: $s p r_{t}$} \\
\hline & \multicolumn{4}{|c|}{ Lag Order } \\
\hline & 0 & 1 & 2 & 3 \\
\hline$\Delta\left(s p r_{t}\right)$ & $\begin{array}{c}0.076 \\
(1.556)\end{array}$ & & & \\
\hline$\Delta\left(\right.$ POS $\left._{t}\right)$ & $\begin{array}{c}0.243 \\
(2.914)^{* *}\end{array}$ & & & \\
\hline$\Delta\left(N E G_{t}\right)$ & $\begin{array}{c}0.116 \\
(1.652)\end{array}$ & $\begin{array}{c}0.026 \\
(0.366)\end{array}$ & $\begin{array}{c}-0.152 \\
(-2.349)^{* *}\end{array}$ & \\
\hline$\Delta\left(s p t_{t}\right)$ & $\begin{array}{c}1.202 \\
(17.231)^{* *}\end{array}$ & & & \\
\hline$\Delta\left(i n t_{t}\right)$ & $\begin{array}{c}-0.019 \\
(-1.096)\end{array}$ & & & \\
\hline
\end{tabular}

\begin{tabular}{|c|c|c|c|c|}
\hline \multicolumn{5}{|c|}{ Panel B: Long-Run Coefficient Estimates } \\
\hline $\mathrm{POS}_{t}$ & $N E G_{t}$ & $s p t_{t}$ & int $_{t}$ & Constant \\
\hline $\begin{array}{c}0.037 \\
(0.111) \\
\end{array}$ & $\begin{array}{c}0.143 \\
(0.430) \\
\end{array}$ & $\begin{array}{c}1.579 \\
(1.677) *\end{array}$ & $\begin{array}{c}0.696 \\
(3.066)^{* *}\end{array}$ & $\begin{array}{c}-8.252 \\
(-1.310)\end{array}$ \\
\hline \multicolumn{5}{|c|}{ Panel C: Diagnostic Statistics } \\
\hline$e c_{t-1}$ & LM & Wald-S & Wald-L & Adj. $R^{2}$ \\
\hline $\begin{array}{c}-0.036 \\
(-1.947)^{* * *}\end{array}$ & $\begin{array}{c}8.433 \\
(0.750)\end{array}$ & $\begin{array}{c}4.176 \\
(0.041)^{* *}\end{array}$ & $\begin{array}{c}0.507 \\
(0.476)\end{array}$ & 0.692 \\
\hline
\end{tabular}

Notes: Numbers inside the parentheses and brackets are $t$-statistics and $p$-values, respectively. ${ }^{* *}$ and ${ }^{*}$ demarcate significance at the $5 \%$ and $10 \%$ levels, respectively. $e c_{t-1}$ denotes an error-correction term. LM represents the Lagrange multiplier test of serial correlation. Wald-S and Wald-L are the Wald tests for short-run asymmetry and long-run asymmetry, respectively. 
Our primary interest is in what happens to the coefficients on oil price increases $\left(\mathrm{POS}_{t}\right)$ and decreases $\left(N E G_{t}\right)$. In the short run, the estimated elasticity of oil price increases is 0.243 , indicating the immediate $0.243 \%$ increase in renewable energy stock prices given a $1 \%$ increase in oil prices (Panel A). This is strongly significant with $t=2.914$ and verifies a positive relationship between rising oil prices and renewable energy stock prices in the short-run. The estimated elasticities of oil price decreases, on the other hand, give mixed results. Even though $\triangle N E G_{t}$ and $\triangle N E G_{t-1}$ have positive coefficients, only $\triangle N E G_{t}$ has a marginally significant $t$ statistic (two-sided $p$-value $=0.10$ ), this is 0.116 , suggesting the immediate $0.116 \%$ decrease in renewable energy stock prices given a $1 \%$ decrease in oil prices. For $\triangle N E G_{t-2}$, however, the coefficient becomes -0.152 and is very significant with $t=-2.349$, indicating the $0.152 \%$ increase in renewable energy stock prices after 2 months given a $1 \%$ decrease in oil prices. Given different signs and magnitudes of the coefficients in $\triangle P O S_{t}$ and $\triangle N E G_{t}$, therefore, the results appear to support short-run asymmetric effects of oil price changes. Indeed, this short-run asymmetric effect is confirmed by the Wald test. The Wald test statistic is 4.176 , and this is the outcome of a $\chi_{1}^{2}$ random variable (Panel C). The $p$-value is less than 0.05 . This rejects the null hypothesis of no short-run asymmetry at the $5 \%$ level, providing evidence of short-run asymmetrical effects. Do short-run effects last into the long-run? This does not seem to be the case in the long-run. Neither $\mathrm{POS}_{t}$ nor $N E G_{t}$ are statistically significant in the long run, although the estimated elasticities are both positive (Panel B). Thus, there is little evidence supporting a positive relationship between rising oil prices and renewable energy stock prices in the long-run. Further, the Wald test produces $\chi_{1}^{2}=0.507$, and the associated $p$-value is 0.476 (Panel C). This fails to reject the null of no long-run asymmetry, thereby providing no evidence of the long-run asymmetrical effects.

The estimated elasticity of stock prices of technology firms for the short-run is 1.202 and for the long-run it is 1.579 (Panels A and B), so that, holding oil prices and interest rates fixed, a 1\% increase in tech stock prices is associated with a $1.202 \%(1.579 \%)$ increase in renewable energy stock prices in the short-run (long-run). The short- and long-run coefficients are both statistically significant, the latter at just about the $10 \%$ level against a two-sided alternative ( $p$-value $=0.096)$. With regard to the interest rate, the estimated coefficient for the short-run is -0.019 , with $t=-1.096$ (Panel A). This is not significant and suggests that interest rates have little effect on stock prices of renewable energy firms in the short-run. The estimated coefficient for the long-run, however, becomes positive (0.696) and the effect is statistically significant with a $t$ statistic of 3.066 (Panel B). Therefore, a higher interest rate increases renewable energy stock prices. This seems counterintuitive. One possibility is that, since higher interest rates are most likely a sign of an economic boom and hence a surging stock market, changes in interest rates may have a positive effect on renewable energy stock prices.

Before leaving this section, we demonstrate that since all the series in Equation (4) are cointegrated, the discussed estimation results do not suffer from the spurious regression problem. For this purpose, we calculate the $F$-statistic to test the null hypothesis that all the five variables have no effect on stock prices of renewable energy firms. This is stated as $H_{0}: \theta_{0}=\theta_{1}=\theta_{2}=\theta_{3}=\theta_{4}=0$. We would reject the null and support cointegration if the computed value of the $F$-statistic exceeds the upper critical value given by Pesaran et al. (2001). In fact, our calculated $F$-statistics is 3.82 . The $10 \%$ upper critical value is about 3.52, and so we soundly reject the null. Therefore, there is evidence of cointegration among the variables. ${ }^{6}$ We also test serial correlation in the error term of Equation (4) in order to detect dynamic misspecification and validate statistical testing (Panel C). Using the usual Lagrange Multiplier (LM) statistic, we obtain $L M=8.433$; in a chi-square distribution with 12 degrees of freedom, this yields a $p$-value $=0.750$. Thus, we do not reject the null and there is little evidence of serial correlation in the residuals, so our model specification and statistical testing are well justified. Finally, stability tests such as cumulative sum (CUSUM) and cumulative sum of squares (CUSUMSQ) reveal that our model performs very well (Figure 1).

6 The error correction coefficient is negative and very significant, providing confirming evidence of cointegration (Panel C). 

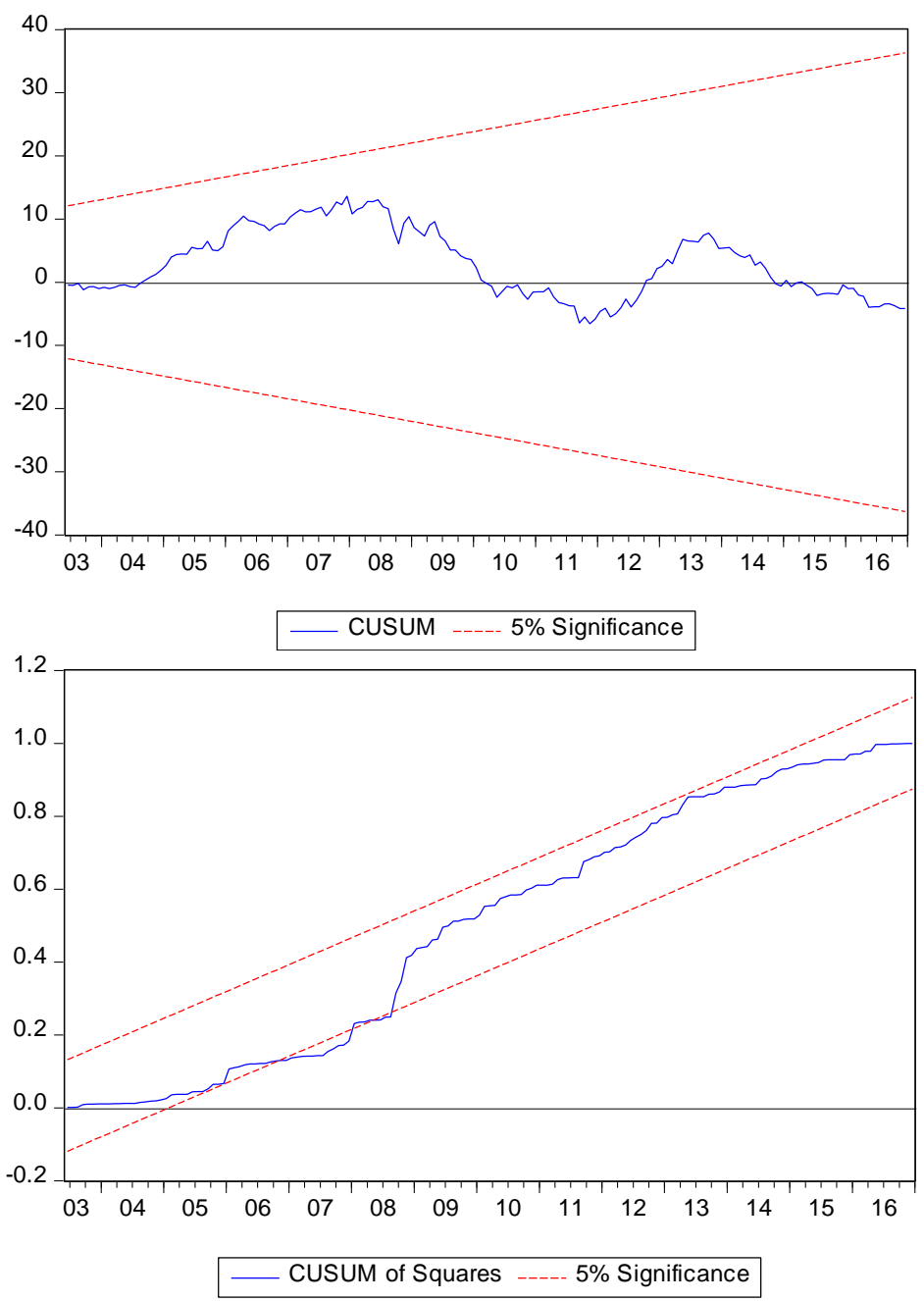

Figure 1. Plots of CUSUM and CUSUMSQ.

\section{Concluding Remarks}

In this article, we revisit one of the rapidly growing empirical questions in energy economics: Is there a positive relationship between crude oil prices and stock prices of renewable energy firms? To explore this question thoroughly, we take specific account of the asymmetrical effects of oil price changes in our modeling process, using the nonlinear ARDL model of Shin et al. (2014). It was hoped that this effort would lend confidence to the robustness and reliability of our findings. Our results show that rising oil prices appear to increase the stock prices of renewable energy firms in the short-run, but not in the long-run. We also find that oil price changes have asymmetrical effects on renewable energy stock prices in the short-run. However, there is no evidence that the short-run asymmetrical effects last into the long-run. Thus, we conclude that potential asymmetrical effects of any changes in the price of crude oil on renewable energy stock prices are a short-run rather than long-run phenomenon. From the findings, we can further make a couple of statements regarding the issue. First, from a methodological perspective, when examining the oil price-renewable stock price nexus, economists need to incorporate the (short-run) asymmetry of oil price fluctuations; otherwise, the empirical models are likely to be misspecified, thereby providing misleading results. Second, from a policy perspective, given the significant short-run (asymmetric) effect of oil prices on renewable stock prices, renewable stocks would be traded more widely and potentially pushing up stock prices and making it more attractive to investors as a short-term investment as the price of oil rises. Thus, 
it seems safe for us to conjecture that the recent spike in oil prices from as low as $\$ 30$ per barrel to more than $\$ 70$ is expected to attract more investors towards renewables, at least in the short-run.

Author Contributions: The corresponding author, J.B., conceived and designed the analysis, revised the paper. The first author, D.L., collected the data, performed the analysis, wrote the paper.

Funding: This research received no external funding.

Conflicts of Interest: The authors declare no conflict of interest.

\section{References}

Baek, Jungho. 2007. The J-curve and the U.S.-Canada forest products trade. Journal of Forest Economics 13: 245-58. [CrossRef]

Baek, Jungho, and Hyun Seok Kim. 2013. Is economic growth good or bad for the environment? Empirical evidence from Korea. Energy Economics 36: 744-49. [CrossRef]

Baek, Jungho, and Won W. Koo. 2009. Assessing exchange rate sensitivity of U.S. bilateral agricultural trade. Canadian Journal of Agricultural Economics 57: 187-203. [CrossRef]

Baek, Jungho, and Dominique Pride. 2014. On the income-nuclear energy- $\mathrm{CO}_{2}$ emissions nexus revisited. Energy Economics 43: 6-10. [CrossRef]

Bahmani-Oskooee, Mohsen, and Jungho Baek. 2015. Further evidence on Orcutt's hypothesis using Korean-US commodity data. Applied Economics Letters 22: 717-24. [CrossRef]

Basher, Syed A., and Perry Sadorsky. 2006. Oil price risk and emerging stock markets. Global Finance Journal 17: 224-51. [CrossRef]

Bekhet, Hussain Ali, and Ali Matar. 2013. Co-integration and causality analysis between stock market prices and their determinates in Jordan. Economic Modelling 35: 508-14. [CrossRef]

Bondia, Ripsy, Sajal Ghosh, and Kakali Kanjilal. 2016. International crude oil prices and the stock prices of clean energy and technology companies: Evidence from non-linear cointegration tests with unknown structural breaks. Energy 101: 558-65. [CrossRef]

Broadstock, David C., Hong Cao, and Dayong Zhang. 2012. Oil shocks and their impact on energy related stocks in China. Energy Economics 34: 1888-95. [CrossRef]

Chaudhuri, Kausik, and Samuel Smiles. 2004. Stock market and aggregate economic activity: Evidence from Australia. Applied Financial Economics 14: 121-29. [CrossRef]

Cong, Rong-Gang, Yi-Ming Wei, Jian-Lin Jiao, and Ying Fan. 2008. Relationships between oil price shocks and stock market: An empirical analysis from China. Energy Policy 36: 3544-53. [CrossRef]

Cummins, Mark, Oonagh Garry, and Claire Kearney. 2014. Price discovery analysis of green equity indices using robust asymmetric vector autoregression. International Review of Financial Analysis 35: 261-67. [CrossRef]

Cunado, Juncal, and Fernando Perez de Gracia. 2014. Oil price shocks and stock market returns: Evidence for some European countries. Energy Economics 42: 365-77. [CrossRef]

Fang, Chung-Rou, and Shih-Yi You. 2014. The impact of oil price shocks on the large emerging countries' stock prices: Evidence from China, India and Russia. International Review of Economics \& Finance 29: 330-38.

Ghosh, Sajal. 2009. Import demand of crude oil and economic growth: Evidence from India. Energy Policy 37: 699-702. [CrossRef]

Irene Henriques, Perry Sadorsky. 2008. Oil prices and the stock prices of alternative energy companies. Energy Economics 30: 998-1010. [CrossRef]

Huang, Roger D., Ronald W. Masulis, and Hans R. Stoll. 1996. Energy shocks and financial markets. Journal of Futures Markets: Futures, Options, and Other Derivative Products 16: 1-27. [CrossRef]

Humpe, Andreas, and Peter Macmillan. 2009. Can macroeconomic variables explain long-term stock market movements? A comparison of the US and Japan. Applied Financial Economics 19: 111-19. [CrossRef]

Iwata, Hiroki, Keisuke Okada, and Sovannroeun Samreth. 2010. Empirical study on the environmental Kuznets curve for $\mathrm{CO}_{2}$ in France: The role of nuclear energy. Energy Policy 38: 4057-63. [CrossRef]

Jalil, Abdul, and Syed F. Mahmud. 2009. Environment Kuznets curve for $\mathrm{CO}_{2}$ emissions: A cointegration analysis for China. Energy Policy 37: 5167-72. [CrossRef]

Johansen, Søren, and Katarina Juselius. 1990. Maximum likelihood estimation and inference on cointegrationWith applications to the demand for money. Oxford Bulletin of Economics and Statistics 52: 169-210. [CrossRef] 
Kang, Wensheng, Ronald A. Ratti, and Kyung Hwan Yoon. 2015. The impact of oil price shocks on the stock market return and volatility relationship. Journal of International Financial Markets, Institutions and Money 34: 41-54. [CrossRef]

Kilian, Lutz, and Cheolbeom Park. 2009. The impact of oil price shocks on the US stock market. International Economic Review 50: 1267-87. [CrossRef]

Kumar, Surender, Shunsuke Managi, and Akimi Matsuda. 2012. Stock prices of clean energy firms, oil and carbon markets: A vector autoregressive analysis. Energy Economics 34: 215-26. [CrossRef]

Kyritsis, Evangelos, and Apostolos Serletis. 2017. Oil Prices and the Renewable Energy Sector. Discussion papers 2017/15. Bergen, Norway: Department of Business and Management Science, Norwegian School of Economics.

Managi, Shunsuke, and Tatsuyoshi Okimoto. 2013. Does the price of oil interact with clean energy prices in the stock market? Japan and the World Economy 27: 1-9. [CrossRef]

Masih, Rumi, Sanjay Peters, and Lurion De Mello. 2011. Oil price volatility and stock price fluctuations in an emerging market: Evidence from South Korea. Energy Economics 33: 975-86. [CrossRef]

Papapetrou, Evangelia. 2001. Oil price shocks, stock market, economic activity and employment in Greece. Energy Economics 23: 511-32. [CrossRef]

Park, Jungwook, and Ronald A. Ratti. 2008. Oil price shocks and stock markets in the US and 13 European countries. Energy Economics 30: 2587-608. [CrossRef]

Pesaran, M. Hashem, Yongcheol Shin, and Richard J. Smith. 2001. Bounds testing approaches to the analysis of level relationships. Journal of Applied Econometrics 16: 289-326. [CrossRef]

Pilinkus, Donatas. 2010. Macroeconomic indicators and their impact on stock market performance in the short and long run: The case of the Baltic States. Technological and Economic Development of Economy 16: 291-304. [CrossRef]

Reboredo, Juan C. 2015. Is there dependence and systemic risk between oil and renewable energy stock prices? Energy Economics 48: 32-45. [CrossRef]

Reboredo, Juan C., Miguel A. Rivera-Castro, and Andrea Ugolini. 2017. Wavelet-based test of co-movement and causality between oil and renewable energy stock prices. Energy Economics 61: 241-52. [CrossRef]

Reynolds, Douglas B., and Jungho Baek. 2012. Much ado about Hotelling: Between the ideas of Hubbert. Energy Economics 34: 162-70. [CrossRef]

Sadorsky, Perry. 1999. Oil price shocks and stock market activity. Energy Economics 21: 449-69. [CrossRef]

Sadorsky, Perry. 2012. Correlations and volatility spillovers between oil prices and the stock prices of clean energy and technology companies. Energy Economics 34: 248-55. [CrossRef]

Sari, Ramazan, Bradley T. Ewing, and Ugur Soytas. 2008. The relationship between disaggregate energy consumption and industrial production in the United States: An ARDL approach. Energy Economics 30: 2302-13. [CrossRef]

Shin, Yongcheol, Byungchul Yu, and Matthew Greenwood-Nimmo. 2014. Modelling asymmetric cointegration and dynamic multipliers in a nonlinear ARDL framework. In Festschrift in Honor of Peter Schmidt. New York: Springer, pp. 281-314.

Shin, Chul, Jungho Baek, and Eunnyeong Heo. 2018. Do oil price changes have symmetric or asymmetric effects on Korea's demand for imported crude oil? Energy Sources, Part B: Economic, Planning and Policy 13: 6-12. [CrossRef]

Stambuli, Benedict Baraka. 2013. Price and income elasticities of oil Demand in Tanzania: An autoregressive approach. Business Management Dynamics 3: 75-83.

Tappen, Samuel, and Jungho Baek. 2016. Can oil tax policy change exploration levels? Empirical evidence from Alaska oil legislation. Energy Sources Part B: Economics, Planning and Policy 11: 1055-60. [CrossRef]

Umekwe, Maduabuchi, and Jungho Baek. 2017. Do oil prices really matter to U.S. shale oil production? Energy Sources, Part B: Economics, Planning, and Policy 12: 268-74. [CrossRef]

Wang, Yudong, Chongfeng Wu, and Li Yang. 2013. Oil price shocks and stock market activities: Evidence from oil-importing and oil-exporting countries. Journal of Comparative Economics 41: 1220-39. [CrossRef]

(C) 2018 by the authors. Licensee MDPI, Basel, Switzerland. This article is an open access article distributed under the terms and conditions of the Creative Commons Attribution (CC BY) license (http://creativecommons.org/licenses/by/4.0/). 